\title{
Fitosociología, Fitoclimatología y Fitogeografía: Tres ciencias en un mismo camino
}

\author{
Ángel Penas, Sara del Río \\ Departamento de Biodiversidad y Gestión Ambiental (Área de Botánica). \\ Instituto de Ganadería de Montaña (Centro Mixto CSIC-ULE). Facultad de \\ Ciencias Biológicas y Ambientales. Universidad de León. 24071. León
}

\begin{abstract}
Resumen
En este trabajo abordamos el estudio e interrelación de tres ciencias: la Fitosociología, que profundiza en el conocimiento de la flora vascular analizando la formación de comunidades vegetales y su relación con el medio, así como estableciendo su carácter climácico, sucesional o antrópico y sus relaciones dinámicocatenales; la Fitoclimatología, que nos ayuda a definir las condiciones climáticas en las que se desarrollan dichas biocenosis y a establecer los umbrales numéricos que delimitan su existencia y, por último; la Fitogeografía, que nos permite delimitar las áreas geográficas de la distribución terrestre de las mismas. Estas ciencias tienen un método científico interdependiente que puede considerarse un todo unitario (camino) para las tres.
\end{abstract}

Palabras clave: Fitosociología, Fitoclimatología, Fitogeografía, Geobotánica global, Medio Terrestre.

Que tres ciencias experimentales hayan encontrado, fundamentándose la una en la otra, la posibilidad de establecer una relación entre ellas, es algo poco frecuente.

Este hecho se produce en el día de hoy, y más aún se producirá en años venideros, entre las ciencias conocidas como Fitosociología, Bioclimatología y Biogeografía, o mejor, para mayor precisión, entre la Fitosociología, la Fitoclimatología y la Fitogeografía.

Ajustándonos a esta afirmación podríamos concluir, como ejemplo, que los sabinares albares pertenecientes a la asociación Juniperetum sabinoorocantabricae (Fitosociología) están en los territorios Picoeuropeano-Ubiñenses (Fitogeografía) y que se desarrollan en un bioclima Templado oceánico submediterráneo (Fitoclimatología).

Pero si en este caso llegamos a la conclusión precedente, partiendo ahora de un tipo de vegetación potencial en principio desconocido (Fitosociología), si nos encontráramos en los territorios del Distrito Babiano-Toriano (Sector Picoeuropeano-Ubiñense) (Fitogeografía), podríamos deducir al ver un sabinar al- 
bar que este pertenecería a la asociación ya mencionada y que las condiciones fitoclimáticas en las que se desarrolla serán las de un bioclima Templado oceánico submediterráneo, incluso más concretamente en un termotipo supratemplado y un ombrotipo subhúmedo-húmedo (Fitoclimatología).

Obviamente, si lo que conocemos es la Fitoclimatología y la vegetación que se desarrolla es un sabinar albar de la asociación mencionada con anterioridad, podremos concluir que los territorios en los que nos encontramos pertenecen a la Región Eurosiberiana, Subregión Altlántica Centroeuropea, Provincia Atlántica Europea, Subprovincia Orocantábrica, Sector Picoeuropeano-Ubiñense, Distrito Babiano-Toriano.

Esta realidad actual y este carácter predictivo es un hecho probado científicamente y de carácter universal, y ello ha sido posible gracias a los avances que en los últimos 50 años han experimentado las tres ciencias mencionadas y la relación establecida entre ellas. Ello nos lleva al final a integrarlas en una única ciencia que conocemos como Geobotánica Global.

Pero vayamos por partes.

Primero definamos qué entendemos por Geobotánica Global y por tal entendemos la ciencia que trata de establecer macro y micromodelos basados en datos florísticos, corionómicos, vegetacionales, bioclimáticos, biogeográficos y funcionales, que tengan información relevante, capacidad de predicción y facilidad de uso. El adjetivo global en el término también alude a que su jurisdicción es la geobiosfera, espacio aéreo y ambiente común de los ecosistemas terrestres, poblados, regidos y definidos esencialmente por las plantas vasculares, desde su aparición en el Paleozoico y que a su vez son función de la evolución y portadoras en sus corias de una precisa información geobotánica. Se ha denominado también Geobotánica integradora.

Como vemos, de la definición se desprende que incluye las tres ciencias a las que nos estamos refiriendo desde un principio (Fitosociología, Fitoclimatología y Fitogeografía), si bien hace uso de otras imprescindibles también para el buen desarrollo de las mismas, partiendo de la Taxonomía y pasando por la Geología, Edafología, Litología, Geografía Física, etc.

Por su parte, la Fitosociología es la ciencia que estudia las comunidades vegetales y sus relaciones con el medio, al tiempo que intenta clasificar y ordenar las comunidades en un sistema jerárquico (Sintaxonomía). Es, por tanto, la ciencia de los sintáxones, en la que la asociación vegetal es su unidad fundamental. Se han utilizado como sinónimos los términos Sociología Vegetal, Fitocenología y Sinecología Vegetal.

Esta ciencia estudia las biocenosis desde una perspectiva botánica (fitoce- 
nosis), es decir, se ocupa de las comunidades vegetales, de sus relaciones con el medio y de los procesos temporales que las modifican. Con toda esta información, a través de un método inductivo y estadístico basado en el inventario de vegetación, trata de crear una tipología jerárquica universal en la que la asociación es la unidad básica del sistema tipológico.

Hoy se distingue, además de la Fitosociología clásica o braunblanquetista (ciencia de las comunidades vegetales o sintáxones), la Fitosociología dinámicocatenal, global o paisajista, en la que sus unidades fundamentales son: en la dinámica, la serie o sigmetum (Fig. 1) y la permaserie o permasigmetum (Fig. 2); y en la catenal, la geoserie o geosigmetum (Fig. 3) y la geopermaserie o geopermasigmetum (Fig. 4).

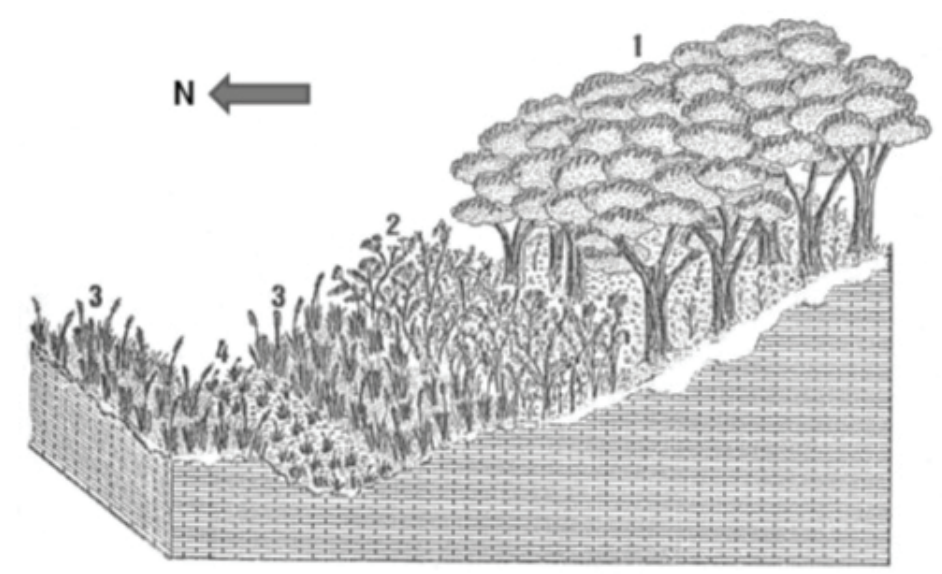

Figura 1. Representación gráfica de una serie de vegetación (climax: 1. Epipactido helleborines-Fagetum sylavaticae y sus etapas de sustitución; 2. Matorral de Pruno spinosaeBerberidetum cantabricae; 3. Matorral camefítico de Glandoro diffusae-Genistetum occidentalis; y 4 . Pastizal vivaz de Helianthemo cantabrici-Brometum erecti) (Autor:T.E. Díaz).

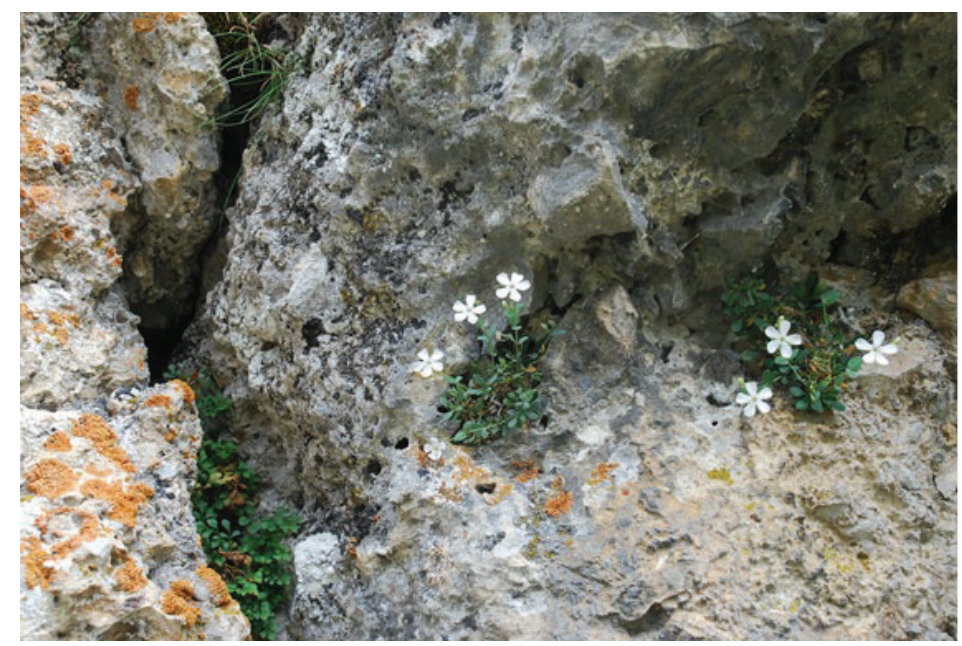

Figura 2. Permaserie de vegetación rupícola de Petrocoptidetum glaucifoliae (Autor: S. del Río). 


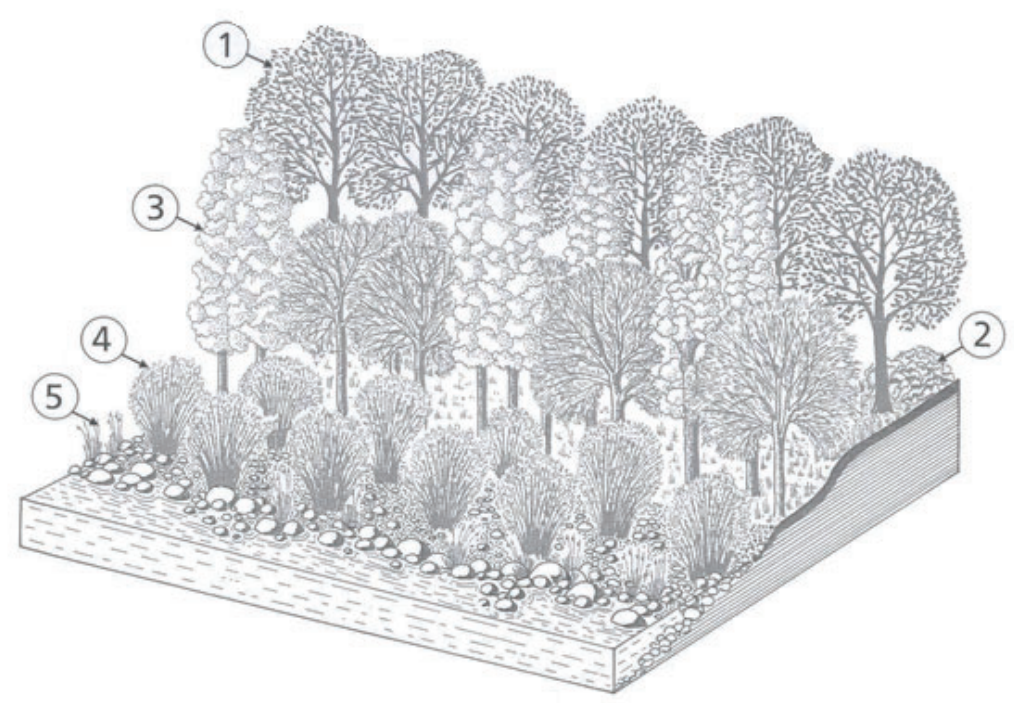

Figura 3. Representación gráfica de una geoserie riparia formada por tres series de vegetación dispuestas catenalmente en relación a su proximidad al río (1. Olmedas o Alamedas; 2. Sebes; 3. Choperas-saucedas; 4 . Saucedas arbustivas; y 5. Comunidades de guijarrales de río) (Autor: T.E. Díaz).

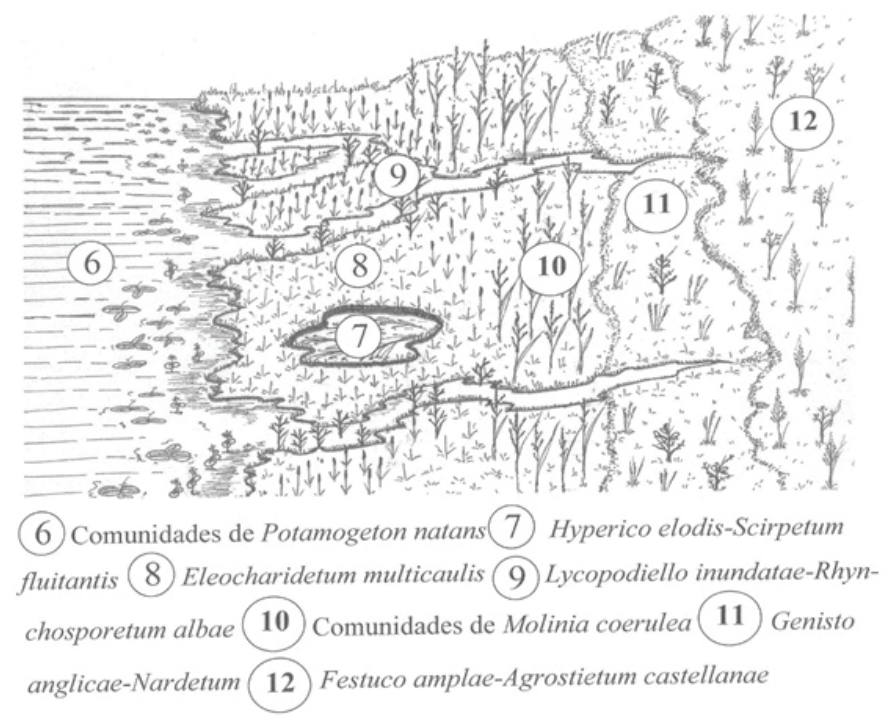

Figura 4. Representación gráfica de una geopermaserie lacustre (Autor: T.E. Díaz).

Parece conveniente distinguir en la Fitosociología dinámico-catenal entre la geoserial, con etapas de sustitución vivaces y anuales y la geopermaserial, sin comunidades vivaces de sustitución no nitrófilas. La primera versaría sobre las geoseries de vegetación, las catenas de teselas y los complejos teselares (Fig. 5); la segunda, geopermaserial, se ocuparía de las geopermaseries, las catenas de permateselas y los complejos permateselares (Fig. 5). 


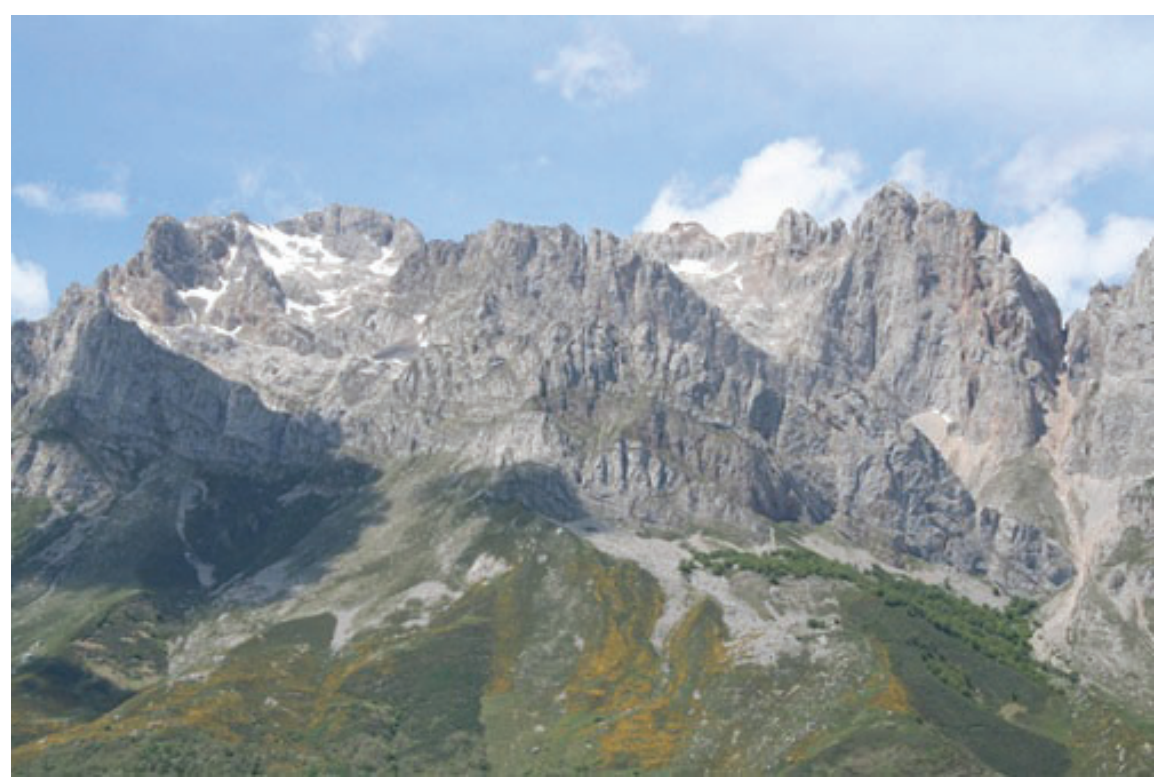

Figura 5. Conjunto de series de vegetación, catenas teselares y complejos teselares de vegetación (parte inferior de la fotografía) y geopermaseries, catenas permatesesales y complejos permateserales (parte superior) en los Picos de Europa (Autor: S. del Río).

En cuanto a la Biogeografía, podemos decir que es la ciencia que estudia la distribución de las especies y de las biocenosis sobre la Tierra. También, teniendo en cuenta las áreas de táxones y sintáxones (Corología vegetal), así como información procedente de otras ciencias de la Naturaleza (Geografía, Edafología, Bioclimatología, Geología, etc.), trata de establecer una tipología jerárquica de los territorios del planeta, cuyas unidades en orden decreciente son: reino, región, provincia, sector, distrito, comarca, célula de paisaje y tesela.

Tal sistematización es uno de los objetivos científicos principales de la Geobotánica actual. La Biogeografía se puede denominar también Fitogeografía, dada la importancia de las especies y comunidades de plantas en la definición y delimitación de sus unidades tipológicas terrestres. La unidad elemental o de menor rango de la Biogeografía es la tesela, que definimos como un espacio geográfico de mayor o menor extensión, homogéneo ecológicamente; es decir, que sólo puede poseer un tipo de vegetación potencial y, en consecuencia, una única secuencia de comunidades sustituyentes. La tesela, la permatesela y sus complejos teselares y permateselares fruto de la geomorfología local, son las únicas unidades biogeográficas que pueden repetirse de modo disyunto. Un amplio espacio geográfico caracterizado por un conjunto de teselas o permateselas y de sus correspondientes complejos, ensambladas por redes de geosigmetos y geopermasigmetos en función del relieve o de los suelos del territorio, constituyen el elemento de paisaje; ej.: penillanuras en horst, valles fluviales, conjuntos lagunares, deltas, altas montañas, etc. La comarca biogeográfica, que también ha si- 
do denominada "mosaico local" (Bolòs, 1963) y "Wuchsdistrict" (Schmithüsen, 1959), debe ser un amplio territorio bien delimitado geográficamente, que posea un conjunto de especies, asociaciones y, sobre todo, geosigmetos topográficos peculiares; ej.: La Sagra Toledana, la Hoya del Bierzo, la Tierra de Barros, etc. El distrito es un conjunto de amplias comarcas biogeográficas, caracterizado por la existencia de una flora particular con especies diferenciales obvias, incluso endémicas en los costeros u oreinos, que permitan su separación de los distritos adyacentes; así como, por un conjunto de asociaciones, series y geoseries cliseriales propias, que faltan en los distritos próximos. En muchos casos, su amplitud y jurisdicción corresponde a la de los antiguos subsectores. El sector es un conjunto de distritos de gran entidad geográfica, que posee táxones, asociaciones y series de vegetación propias; así como que muestra geoseries topográficas y geoclinosecuenciales originales que, en general, suelen deberse a la existencia de comunidades climatófilas permanentes y subseriales endémicas. La provincia es un vasto territorio que, además de poseer gran número de endemismos o subelemento propio, tiene unas particulares macroseries y geomacroseries. También es característico de cada provincia una peculiar zonación altitudinal de la vegetación. La región es un territorio muy extenso que posee una flora o elemento florístico original en el que existen especies, géneros o incluso familias endémicas; asimismo, dispone de megaseries y geomegaseries particulares y, en consecuencia, pisos bioclimáticos propios. Por último, el reino es la unidad suprema de la Biogeografía y en él, además de consideraciones taxonómicas y ecosistemáticas, entra en juego el origen de la flora y fauna, la formación de los grandes continentes, el clima, los paleoclimas, etc.

Como ya es tradicional en esta ciencia, las denominaciones de las unidades biogeográficas se acuñan como gentilicios en base a nombres geográficos conocidos, que se estima son más o menos coincidentes, informativos o representativos del área que trata de expresar. Ortográficamente, todas las unidades biogeográficas se consideran nombres propios de lugar. Si el nombre se forma por yuxtaposición de dos nombres geográficos, estos se unen por un guion, manteniendo las mayúsculas por su condición de nombre propio. Parece conveniente recordar que sólo a través de su diagnosis y de los correspondientes mapas se pueden delimitar con precisión los territorios biogeográficos (Fig. 6).

Todas las unidades biogeográficas, excepto la tesela y permatesela, deben ser territorios contiguos por vía terrestre o marina que incluyan los accidentes orográficos y diversidad litológica que pueda existir en su área. A veces, en los territorios biogeográficos de entidad, aparecen introgresiones de otras adyacentes y, en ocasiones, tales islas pueden llegar a ser frecuentes en comarcas de li- 


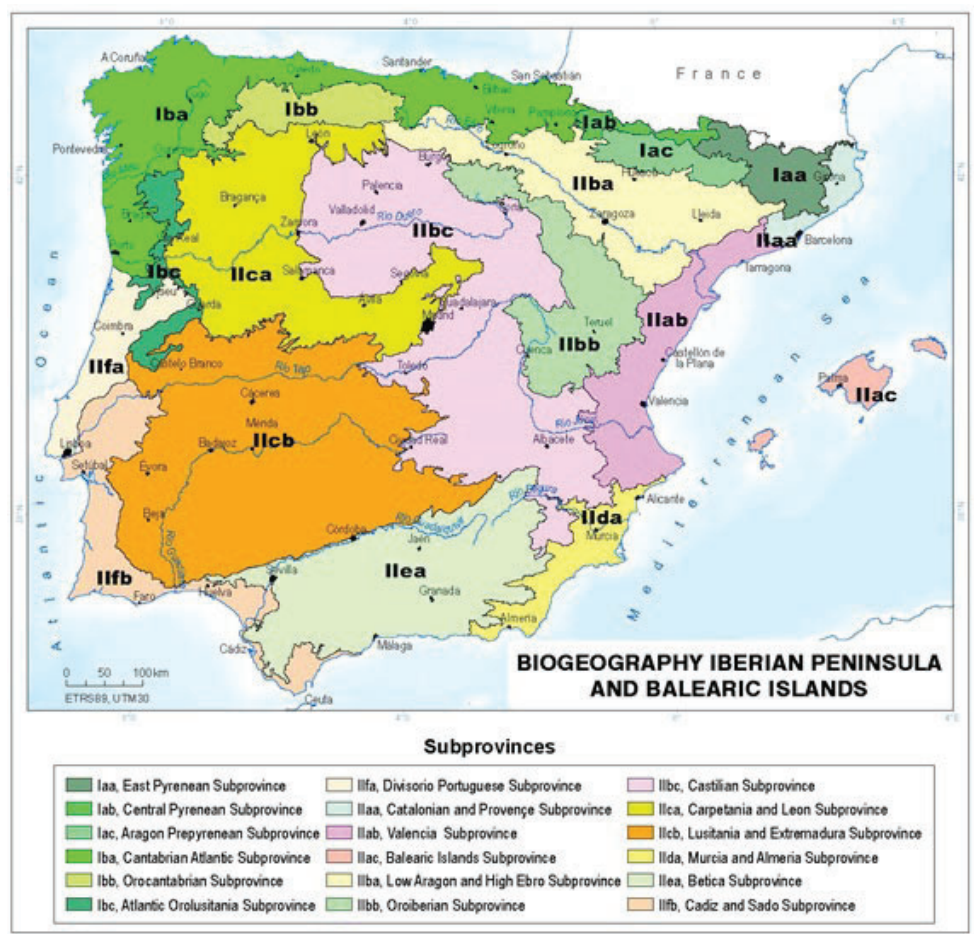

Figura 6. Mapa fitogeográfico de la Penísula Ibérica e Islas Baleares a nivel subprovincial (Rivas-Martínez et al., 2017).

tología variada o en áreas próximas a fronteras regionales o provinciales. Su posible independencia tipológica, siempre de rango inferior a aquella en la que se introgrede, depende de su originalidad, riqueza florística y fitocenótica, así como de su extensión superficial. Uno de los criterios tradicionalmente utilizados en el reconocimiento y delimitación de áreas biogeográficas de entidad propia es el discernimiento y cartografía de aquellos táxones (familias, géneros, especies y subespecies) que tienen una distribución territorial ceñida a un área concreta. A tales táxones se les ha llamado endemismos. Ventajosamente, los endemismos se han utilizado en la definición y delimitación de las unidades corológicas o biogeográficas (provincias, sectores) al formar parte del subelemento fitogeográfico que las caracteriza. Asimismo, los endemismos (táxones o sintáxones) de mayor área o regionales, y los existentes por razones migratorias dispersos en varias regiones biogeográficas, constituyen el elemento o geoelemento fitogeográfico. En los tiempos actuales, con el desarrollo de la Fitosociología dinámico-catenal y el conocimiento sintaxonómico, bioclimático, edáfico y cartográfico de amplios territorios de la Tierra, las series y geoseries de vegetación han pasado a ser criterios esenciales sobre todo en la delimitación y definición de las unidades biogeográficas (Fig. 6).

Por último, hablaremos de la Fitoclimatología, que estudia la reciprocidad entre el clima y la distribución de los seres vivos y de sus comunidades en la Tierra. Esta disciplina comenzó a estructurarse a partir de la relación de los valo- 
res numéricos del clima (temperatura y precipitación) con los areales de las plantas y las formaciones vegetales, para añadir más adelante información de las biogeocenosis y recientemente conocimientos de la Fitosociología dinámico-catenal, es decir, de los sigmetos, geosigmetos y geopermasigmetos (series, geoseries y geopermaseries de vegetación). En los últimos años el Prof. Rivas-Martínez ha tratado de poner a punto una clasificación bioclimática de la Tierra que tenga jurisdicción en toda la geobiosfera. Las razones del empeño son llegar a disponer de una tipología bioclimática fácilmente cuantificable que muestre una relación ajustada entre los componentes vegetacionales y los valores del clima, al tiempo que, habida cuenta del elevado valor predictivo de las unidades bioclimáticas, puedan utilizarse en otras ciencias, en los programas de estudio y conservación de la biodiversidad, así como en la obtención de recursos agrícolas y forestales. El conocimiento cada vez más detallado de la distribución de la vegetación sobre la Tierra, así como las modificaciones en el aspecto y composición de la vegetación potencial y de sus etapas de sustitución causadas por factores climáticos, edáficos, geográficos y antrópicos, está permitiendo que cada día puedan reconocerse con mayor precisión y objetividad las fronteras bioclimáticas y vegetacionales. Una vez conocidos y cartografiados los límites o fronteras de las series, geoseries y geopermaseries de vegetación, se han podido calcular los valores bioclimáticos numéricos umbrales que los discriminan (Rivas-Martínez et al. 2011). De este modo, progresivamente se han ido delimitando y ajustando los espacios correspondientes a las unidades bioclimáticas (bioclimas, termotipos y ombrotipos). Los modelos biofísicos así establecidos han demostrado tener una elevada reciprocidad en el binomio clima-vegetación, lo que está permitiendo realizar mapas bioclimáticos y biogeográficos mundiales bastante más precisos (Fig. 7,

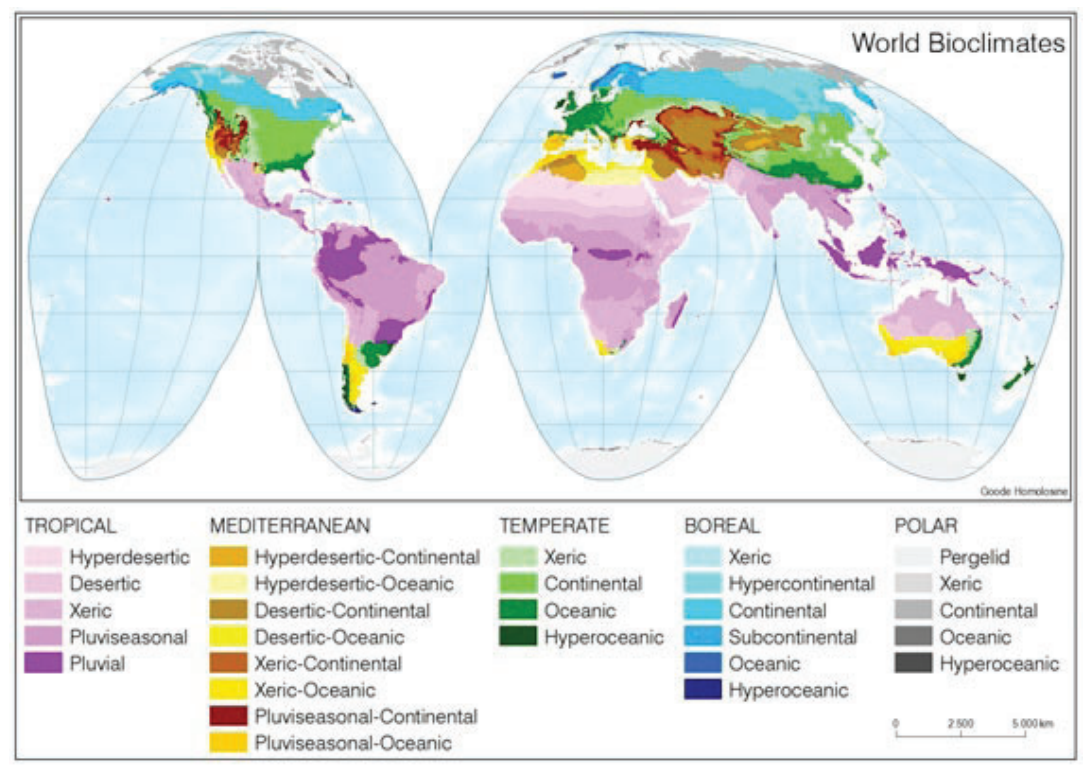

Figura 7. Mapa de Bioclimas de la Tierra (Rivas-Martínez et al., 2011). 
8, 9 y 10). Una consecuencia práctica es haber conseguido un valor predictivo recíproco en toda la Tierra, solamente conociendo los datos del clima o recíprocamente los tipos de vegetación.

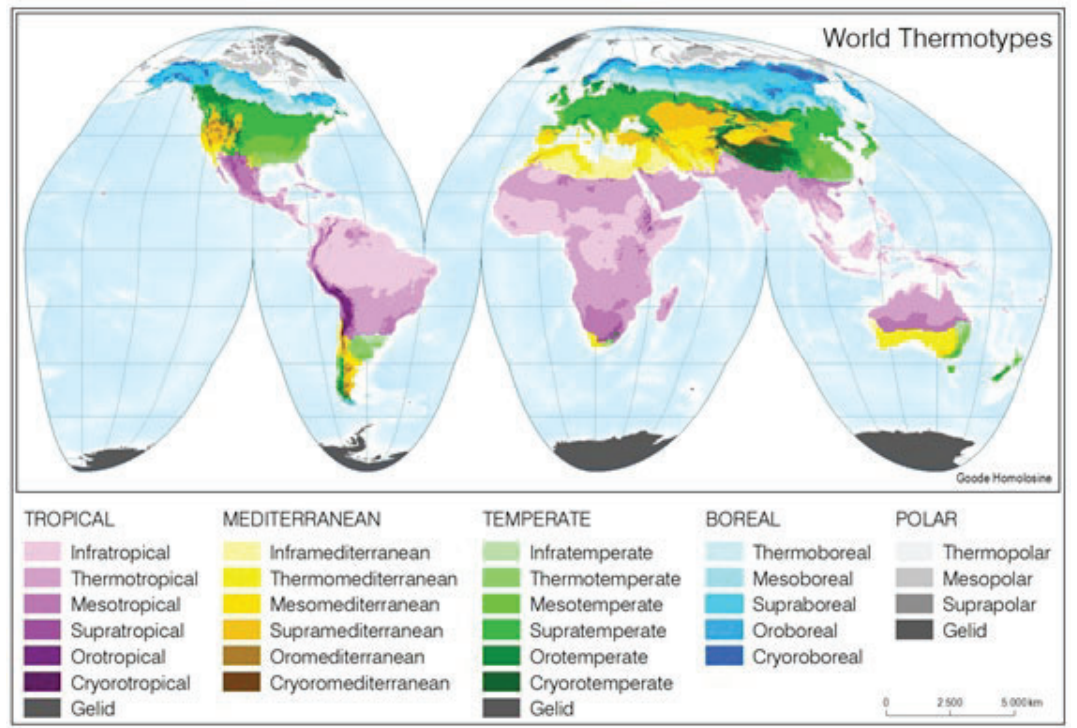

Figura 8. Mapa de Termotipos de la Tierra (Rivas-Martínez et al., 2011).

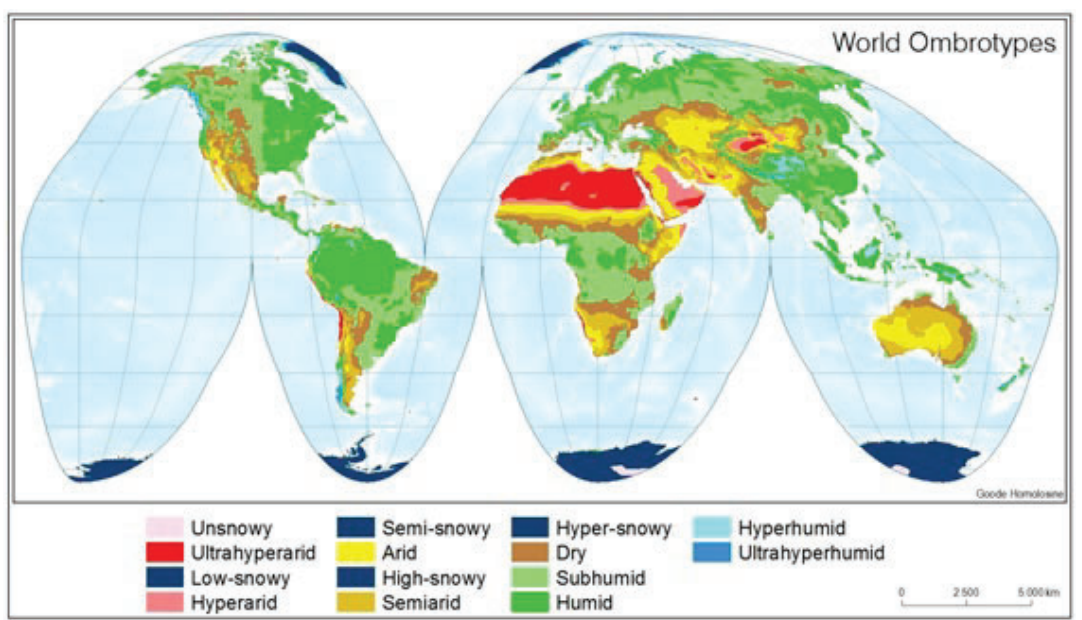

Figura 9. Mapa de Ombrotipos de la Tierra (Rivas-Martínez et al., 2011).

En la clasificación bioclimática global que utilizamos se reconocen cinco macrobioclimas, veintiocho bioclimas y once variantes bioclimáticas. El macrobioclima es la unidad tipológica suprema del sistema de clasificación bioclimática. Se trata de un modelo biofísico ecléctico, delimitado por determinados valores climáticos y vegetacionales, que posee una amplia jurisdicción territorial y que está relacionado con los grandes tipos de climas, de biomas y de regiones biogeográficas que se admiten en la Tierra. Hay cinco macrobioclimas: Tropical, 


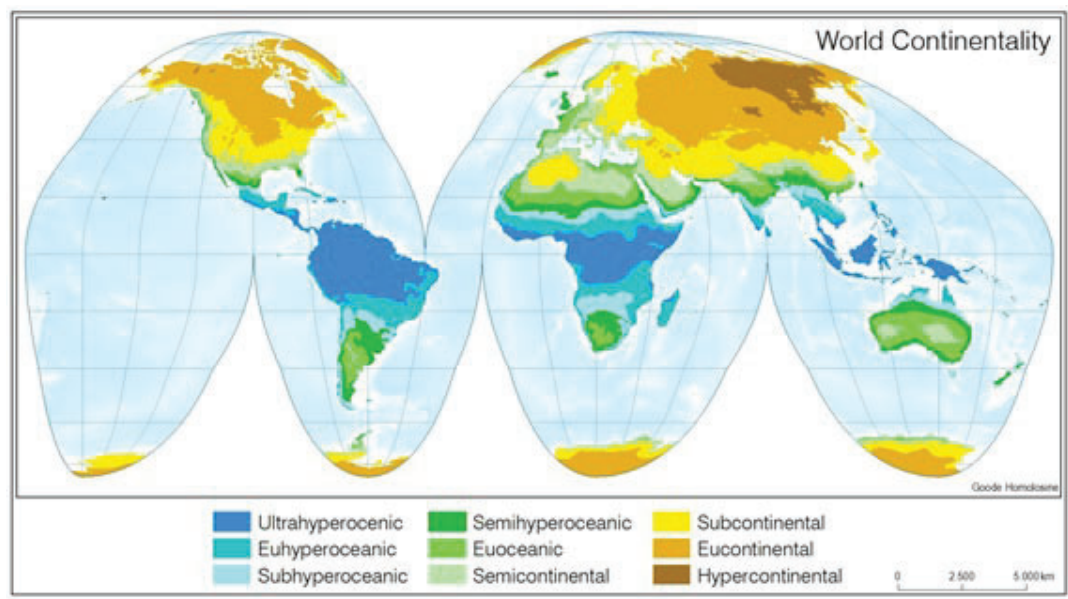

Figura 1o. Mapa de tipos de Continentalidad de la Tierra (RivasMartínez etal., 2011).

Mediterráneo, Templado, Boreal y Polar. Cada uno de ellos y cada una de sus veintiocho respectivas unidades subordinadas o bioclimas, están representados por un conjunto de formaciones vegetales, biocenosis y comunidades vegetales propias. En los bioclimas, además de sus variaciones ombro-termoclimáticas o pisos bioclimáticos: termotipos y ombrotipos, se ha reconocido en función de los ritmos estacionales de la precipitación un cierto número de unidades que se han denominado variantes bioclimáticas.

Sin entrar en su conocimiento pormenorizado, podemos señalar aquí cuál es el reparto de la superficie terrestre entre los cinco macrobioclimas (Fig. 11) reconocidos y ya mencionados, así como la proporción que en cada uno de ellos se corresponde con los diferentes bioclimas existentes en su seno (Fig. 12, 13, 14, 15 y 16). También se presentan los distintos termotipos (Fig. 17, 18, 19, 20 y 21) y ombrotipos/quionotipos (Fig. 22) de cada macrobioclima a nivel mundial. Por último, se muestran los niveles de continentalidad existentes en la superficie terrestre (Fig. 23).

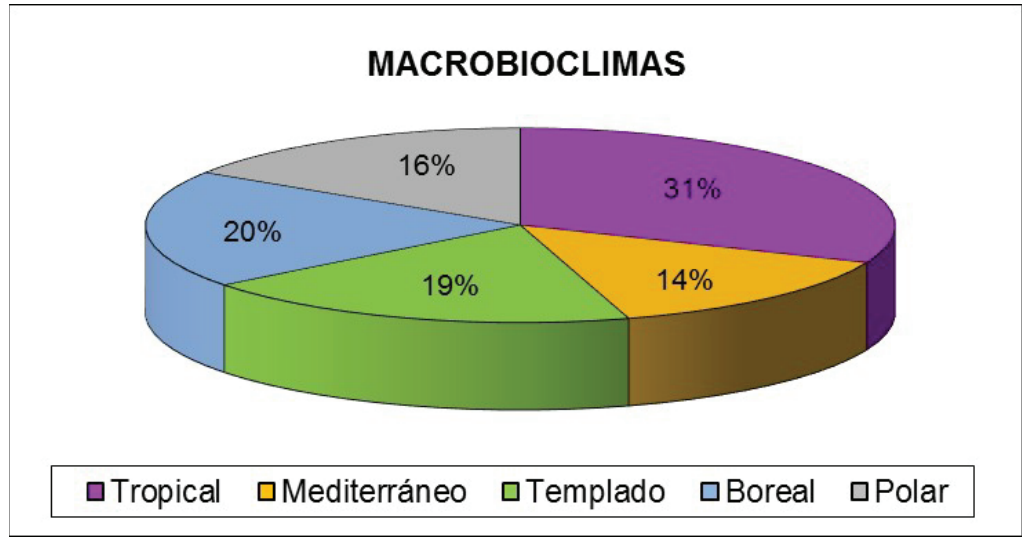

Figura 11. Distribución porcentual de los Macrobioclimas. 


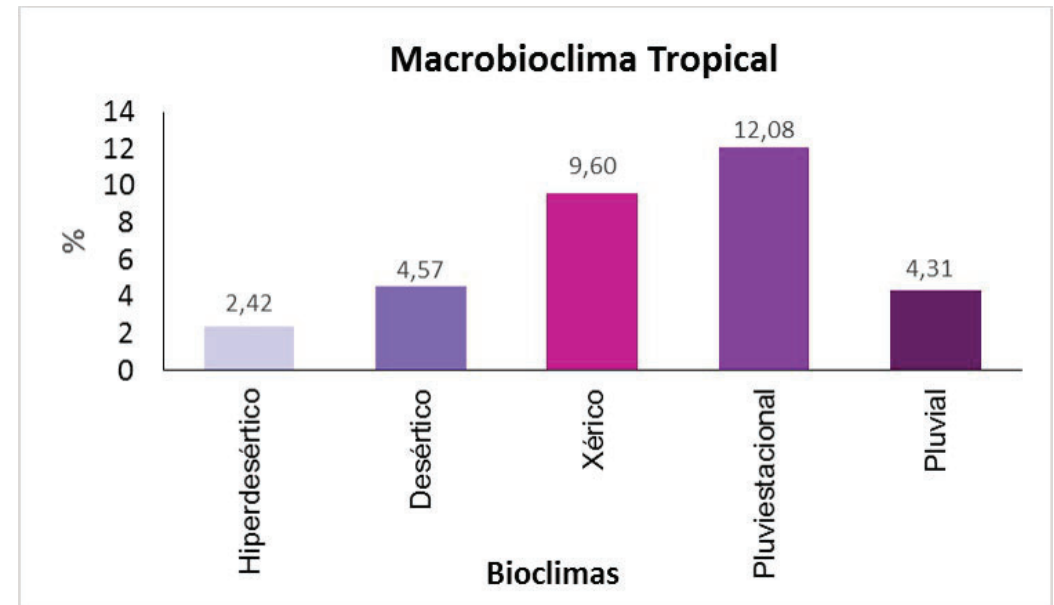

Figura 12. Distribución porcentual de los Bioclimas Tropicales.

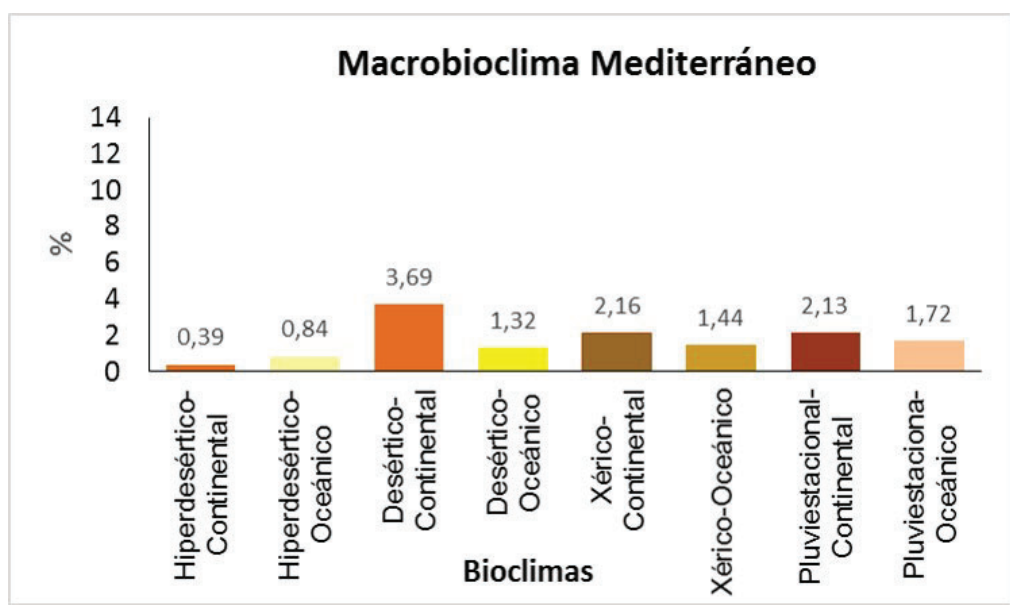

Figura 13. Distribución porcentual de los Bioclimas Mediterráneos.

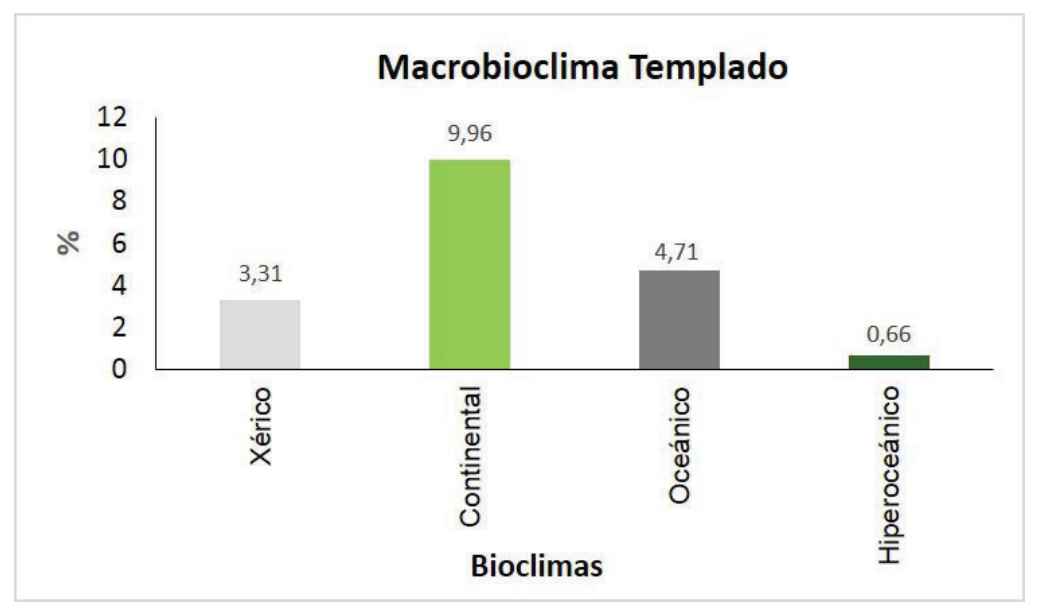

Figura 14. Distribución porcentual de los Bioclimas Templados. 


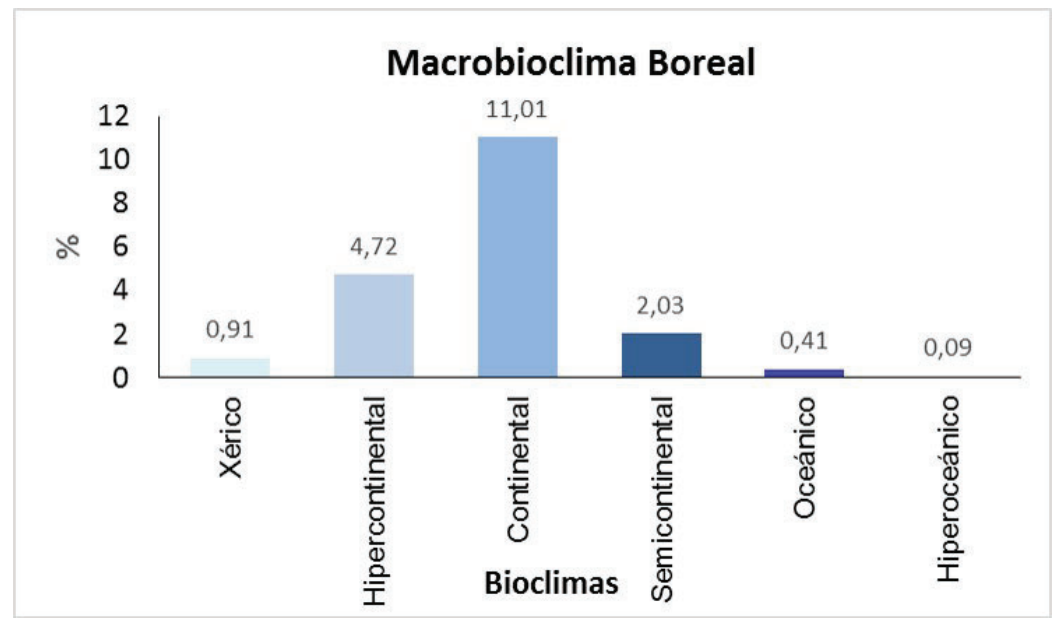

Figura 15. Distribución porcentual de los Bioclimas Boreales.

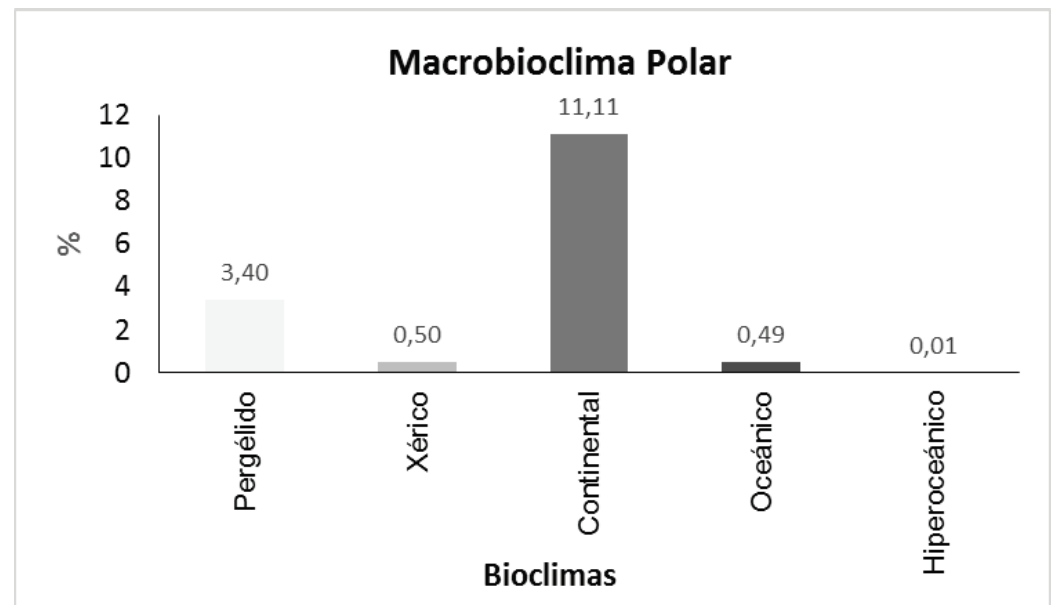

Figura 16. Distribución porcentual de los Bioclimas Polares.

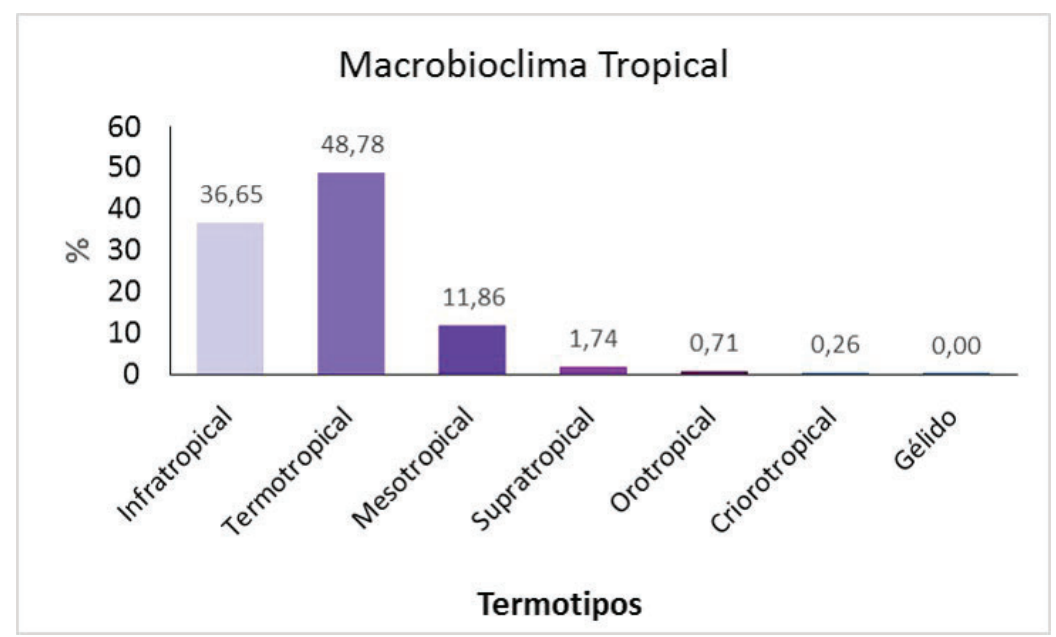

Figura 17. Distribución porcentual de los Termotipos Tropicales. 


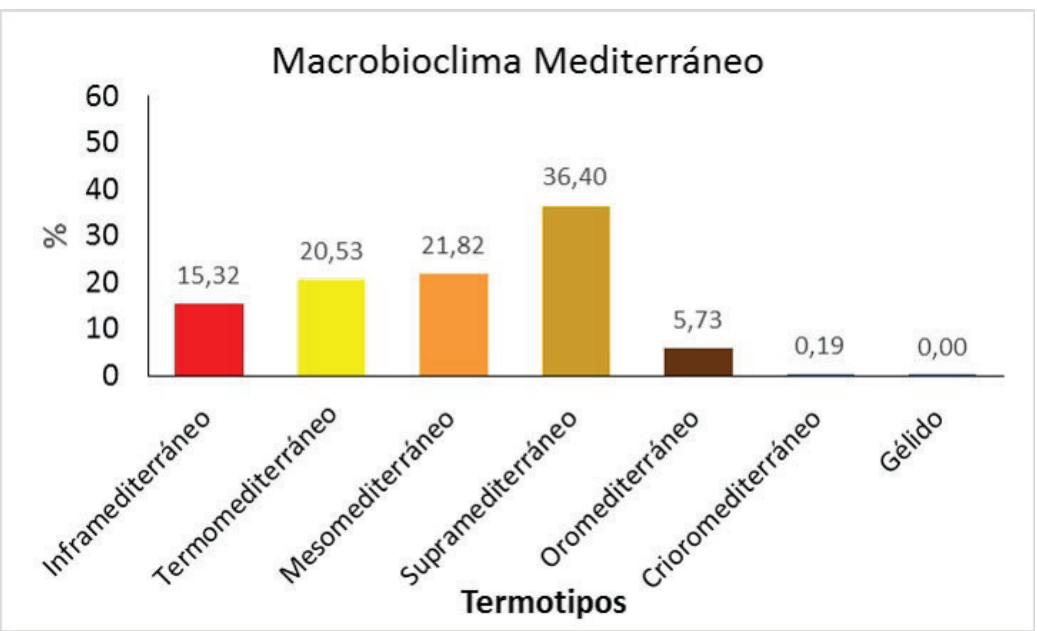

Figura 18. Distribución porcentual de los Termotipos Mediterráneos.

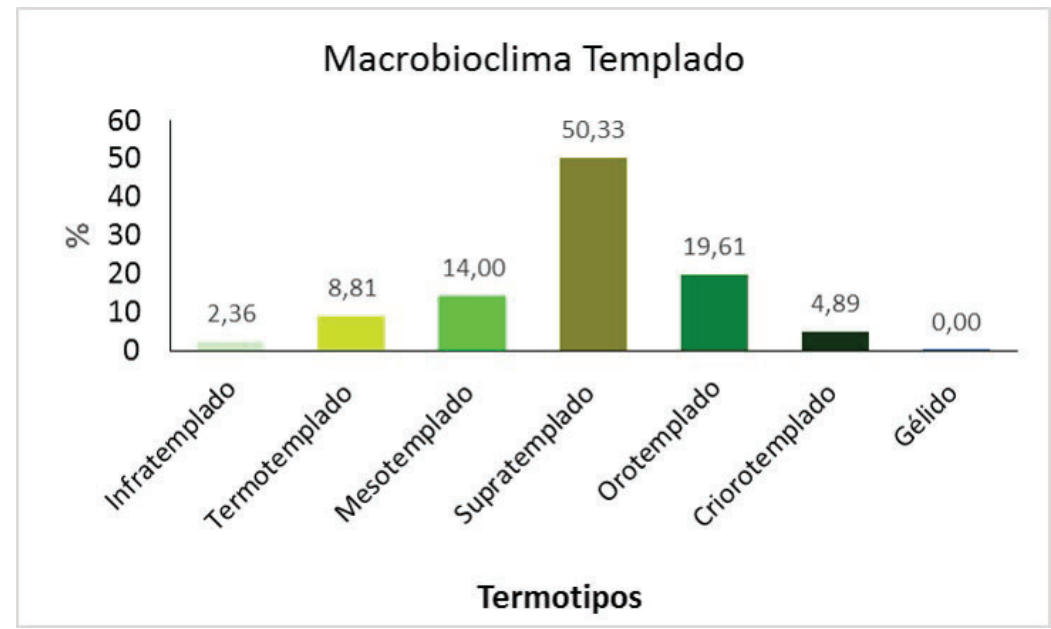

Figura 19. Distribución porcentual de los Termotipos Templados.

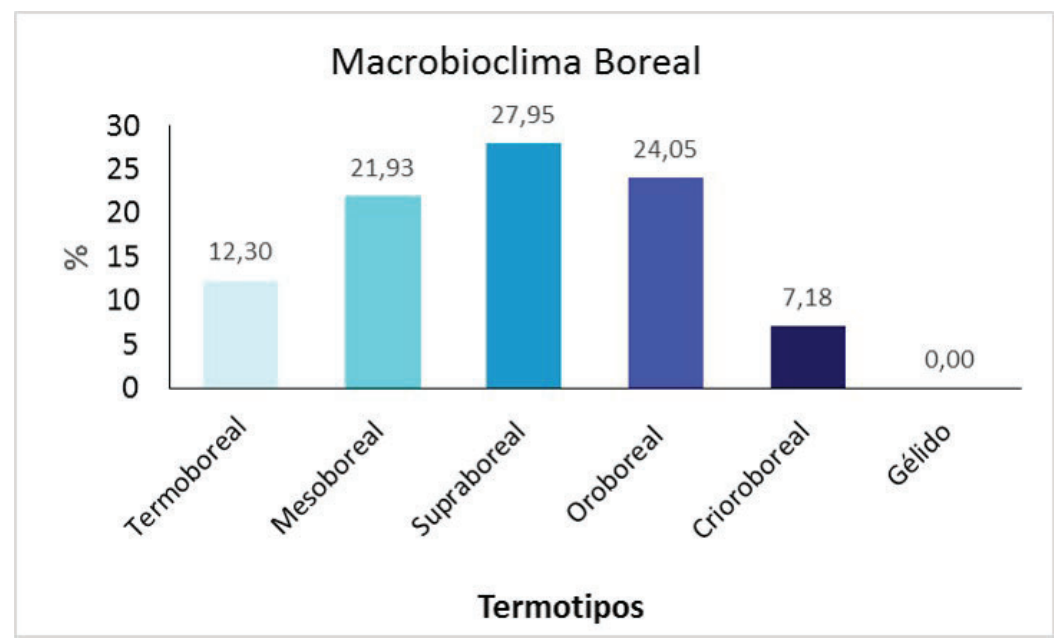

Figura 20. Distribución porcentual de los Termotipos Boreales. 


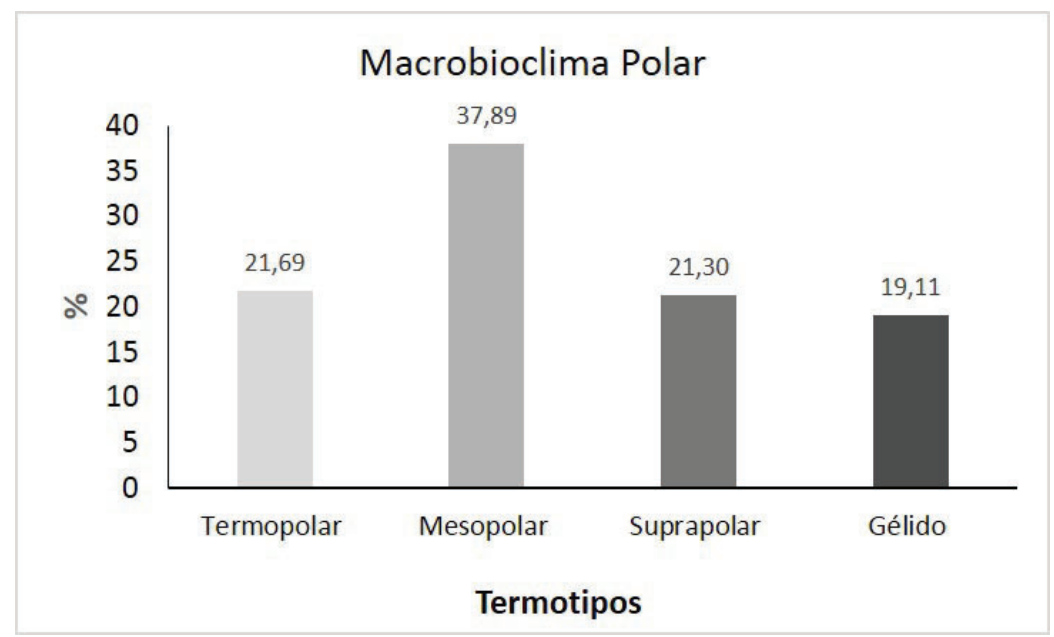

Figura 21. Distribución porcentual de los Termotipos Polares.

Ombrotipos/Quionotipos

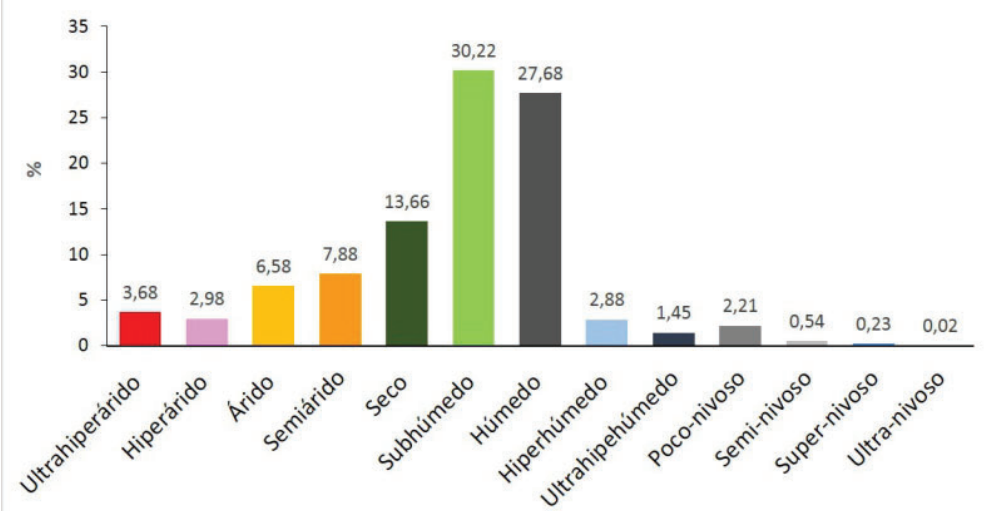

Figura 22. Distribución porcentual de los Ombrotipos.

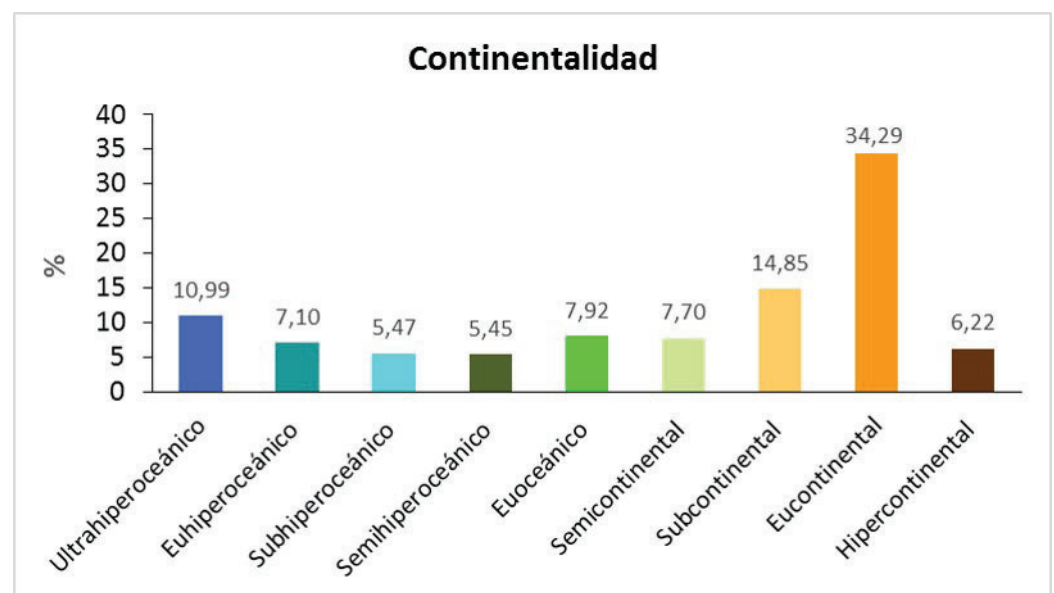

Figura 23. Distribución porcentual de los Tipos de Continentalidad. 


\section{Bibliografía}

Bolòs, O. 1963. Botánica y Geografía. Memorias de la Real Academia de Ciencias y Artes de Barcelona 34:443-480

Rivas-Martínez, S., Rivas-Sáenz, S. y Penas, A. 2011. Worldwide bioclimatic classification system. Global Geobotany 1: 1-634 + 4 maps

Rivas-Martínez, S., Penas, A., Díaz-González, T.E., Cantó, P., del Río, S., Costa, J.C., Herrero, L. \& Molero, J. 2017. Biogeographic Units of the Iberian Peninsula and Baelaric Islands to District Level. A Concise Synopsis. In: Loidi J. (eds) The Vegetation of the Iberian Peninsula. Plant and Vegetation, vol 12, pp 131-188. Springer

Schmithüsen, J. 1959. Allgemeine Vegetationsgeographie. Berlin 